\title{
João de Deus Ramos e sua abordagem educativa
}

\author{
(João de Deus Ramos and his educational approach)
}

\author{
EIsa RODRIGUES \\ Museu João de Deus
}

\begin{abstract}
RESUMO: Este artigo surge da investigação feita para o projeto INOVAR - Roteiros da inovação pedagógica: escolas e experiências de referência em Portugal no seculo XX (20162019), do qual o Jardim-Escola João de Deus (Lisboa) é um exemplo de estudo e tem por objetivo primordial analisar as suas práticas pedagógicas. Devido ao facto de 0 Jardim-Escola em análise ser centenário, delimitei a minha reflexão ao arco temporal que vai desde a sua abertura ao público em 1915 até ao falecimento do seu fundador em 1953.
\end{abstract}

PALAVRAS-CHAVE: metodologia João de Deus; alfabetização; Educação dos sentidos; Edifício escolar; Higiene.

ABSTRACT: This article draws on research carried out for the INOVAR Project - Itineraries of pedagogical innovation: reference schools and experiences in Portugal in the 20th century (2016-2019), presenting João de Deus Kindergarten (Lisbon)as the case study, with a focus on the school's pedagogical practices. Due to the fact that this kindergarten dates back to over one hundred years, this research was limited to the time frame from its opening in 1915 until the death of its founder in 1953.

KEY-WORDS: João de Deus methodology; Literacy acquisition; Education of the senses; School building, Hygiene.

\section{Introdução}

João de Deus, poeta e pedagogo, autor do método de leitura Cartilha Maternal ou Arte de Leitura e fundador da Associação de Escolas Móveis pelo Methodo João de Deus deixara um legado que era preciso preservar, divulgar e expandir. Este desejo encontrou eco em João de Deus Ramos, um propagandista dedicado do método de seu pai e um homem deveras interessado nas pedagogias modernas. Enquanto João de Deus tivera a iniciativa de criação da Associação de Escolas Móveis pelo Método João de Deus que formava professores e os enviava em missões de alfabetização gratuitas aos que solicitassem a ida de um professor à sua localidade, formando classes heterogéneas, compostas de crianças e adultos de ambos os sexos, João de Deus Ramos estava, sobretudo, preocupado com a educação pré-escolar e o abandono a que a criança estava votada; realidade bem patente nos centros urbanos portugueses. Para resolver este problema 
criou os Jardins-Escolas João de Deus. O primeiro foi inaugurado em Coimbra, em 1911. Seguiram-se os de Figueira da Foz e de Alcobaça, ambos inaugurados em 1914, tendo 0 de Lisboa começado a receber crianças em 1915. A Associação de Jardins-Escolas João de Deus conta atualmente com uma rede nacional de quarenta Jardins-Escolas, situadas em Portugal continental e insular.

\section{A génese dos jardins-escolas}

Desde jovem que João de Deus Ramos manifestava a sua apetência por colmatar o problema educativo em Portugal. Conta-nos João de Barros, seu condiscípulo do curso jurídico na Universidade de Coimbra, que

Estudante ainda, e ele estudante como eu, observei logo em João de Deus Ramos o interesse, 0 carinho, a atenção que dedicava a assuntos pedagógicos - e, sobretudo, à mesquinha sorte da criança pobre portuguesa, abandonada de amparo escolar na idade em que se forma a inteligência e em que se plasma a sensibilidade. ${ }^{1}$

João de Deus Ramos queria edificar Jardins-Escolas. Por isso empreendeu viagens pela Europa a fim de estabelecer contacto com outros pedagogos. Em novembro de 1907 viajou com João de Barros que era professor pensionista. Ao passar por Madrid conheceram Julio Nombela y Campos $^{2}$ e Francisco Giner de los Ríos ${ }^{3}$. 0 roteiro seguiu por Bordéus e Paris onde João de Deus Ramos continuou a estabelecer contactos pessoais com diversos tipos de ensino. De regresso a Lisboa conversou com o arquiteto Raul Lino, que a 2 de janeiro de 1908 lhe escreveu uma missiva a propósito da edificação do primeiro Jardim-Escola que viria a ser construído em Coimbra

[...] estou completamente ao dispor de V. Exª . para elaborar este projeto que muito me interessará e sinto-me feliz por poder colaborar [...]. Depois de ouvir as explicações de V. Ex ${ }^{\mathrm{a}}$. estou certo que me dedicarei com entusiasmo a este trabalho que por ser inspirado nas teorias de Tolstoi deve também obdecer a Ruskin na parte artística. ${ }^{4}$

Em 1908 João de Deus Ramos empreendeu nova viagem passando por Génova, Turim, Como, Lugano, Lucerna, Berna e Genebra, onde estabeleceu contacto com pedagogias, conheceu diretores de escolas e comprou as mais recentes obras pedagógicas ${ }^{5}$ que encontrou nas livrarias. Do Consulado Português em Genebra ${ }^{6}$ obteve a seguinte permissão: «Monsieur João de Deus Ramos est autorisé à visiter les Écoles de la Ville et les directeurs sont priés de lui donner les renseignements qui lui sont nécessaires. Genève, le

\footnotetext{
1 João de Barros, Um grande educador: João de Deus Ramos e a obra dos Jardins-Escolas (Lisboa: Oficinas Gráficas, 1933), 7-8.

2 Julio Nombela y Campos (1866-1908), escritor e jornalista, diretor da revista mensal ilustrada Vida Intectual.

${ }^{3}$ Francisco Ginér de los Ríos (1839-1915), pedagogo, filósofo e ensaísta. Fundador e diretor da Institución Libre de Enseñanza.

${ }^{4}$ Correspondência para João de Deus Ramos, 1908: Janeiro - Maio, Museu João de Deus.

${ }^{5}$ Estas obras são parte integrante do acervo do Museu João de Deus.

${ }^{6}$ Consulat de Sa Majesté Très-Fidèle le Roi de Portugal. Genève.
} 
18 Sepbre 1908. Le Conseiller Administratif délégué». ${ }^{7}$ Dos contactos que fez aprofundou os seus conhecimentos sobre o movimento de Escola Nova ou Escola Ativa, na qual a criança tem liberdade reflexiva, autonomia em relação ao adulto e responsabilidade de manter a ordem na escola. Estudou minuciosamente a pedagogia de Friedrich Froëbel, Johann Heinrich Pestalozzi, Jean-Ovide Decroly e Maria Montessori. A sua chegada a Portugal não passou despercebida à imprensa que já noticiava a ideia de criação do primeiro Jardim-Escola a ser construído em Coimbra e indicava que:

\begin{abstract}
No Jardim-Escola a criança encontrará o conchego do lar doméstico no carinho maternal de uma professora dedicada, aprenderá a conhecer a natureza no contacto permanente com ela e no ensino ao ar livre, fortificará o corpo à custa do cumprimento rigoroso dos preceitos higiénicos, desenvolverá o gosto pelo trabalho nos rudimentos interessantes dos exercícios manuais, ficará, por fim, a conhecer a sua língua pela aplicação nacional do método de João de Deus estudado com a máxima liberdade e procurando estimular-lhe a vontade e a curiosidade de saber. $^{8}$
\end{abstract}

Confiante em que a criação de escolas infantis seria o rumo a seguir propôs em Assembleia Geral, de 13 de fevereiro de 1908, a alteração do nome da associação para Associação de Escolas Móveis pelo Methodo João de Deus, Bibliothecas Ambulantes e Jardins-Escolas e acrescentou aos estatutos que a Associação tinha, entre outras finalidades, «Instituir «jardins-escolas» para crianças de três a sete anos, onde seja aplicado, em toda a sua plenitude, o espírito e doutrina da obra educativa de João de Deus, modelando assim um tipo português de escola infantil». ${ }^{9}$ Em 1911 fez nova alteração aos estatutos da Associação especificando que os Jardins-Escolas seriam edificados «nos principais centros do país e em bairros de população operária» ${ }^{10} \mathrm{e}$, dando continuidade às suas pesquisas, voltou a sair do país em busca de ajuda pedagógica, passando por Abancourt, Milly-sur-Thérain e Neuville-Vault e Bruxelas.

\title{
A construção do jardim-escola joão de deus (Lisboa)
}

A ideia de edificação duma "Escola-Monumento»"11 foi concebida em 1909 por um grupo de intelectuais e artistas, liderado por Afonso Lopes Vieira, que para alcançar tal objetivo, criou uma subscrição pública, em Lisboa, sendo o primeiro anseio da Sub-Comissão Executiva $^{12}$ a aquisição de terreno próprio. No ano seguinte, o deputado Aquiles Gonçalves Fernandes ${ }^{13}$ apresentou na Câmara de Deputados um projeto de lei que concedia à Associação de Escolas Móveis pelo Método João de Deus o terreno pertencente ao Estado, em frente ao Liceu Pedro Nunes, para edificação da Escola-Monumento. Após aprovação

\footnotetext{
${ }^{7}$ Correspondência para João de Deus Ramos, 1908: Junho - Dezembro, Museu João de Deus.

8 "Jardim-Escola João de Deus: Propaganda para aquisição de fundos», Defesa, 11/11/1908.

${ }^{9}$ Associação de Escolas Móveis pelo Methodo João de Deus, Bibliothecas Ambulantes e Jardins-Escolas (1908). Estatutos. Lisboa: Typographia Minerva Central e Annuario Commercial. Artigo 1 - 4ํㅡㄴ 3.

${ }^{10}$ Associação de Escolas Móveis pelo Methodo João de Deus, Bibliothecas Ambulantes e Jardins-Escolas (1911). Estatutos. Lisboa: Typographia Leiria.

${ }^{11}$ Jardim-Escola João de Deus (Lisboa) e Museu João de Deus.

${ }^{12}$ Cristovão Aires, Afonso Lopes Vieira, José de Figueiredo, Coelho de Carvalho e Abel Botelho.

${ }^{13}$ Aquiles Gonçalves Fernandes (1880-1915), advogado, sócio da Associação de Escolas Móveis pelo Método João de Deus. Amigo e admirador de João de Deus Ramos.
} 
do projeto, foi publicada a lei em Diário do Governo de 18 de maio ${ }^{14}$ e imediatamente foram tomadas todas as diligências práticas da execução do projeto, conforme descrito no relatório anual de atividades: "Feita a planta do Jardim-Escola João de Deus, em Lisboa, pelo distinto arquiteto Raúl Lino, e já aprovada pelo município da capital ${ }^{15}$, dentro de pouco tempo começará a construção, e é de esperar que em Outubro de 1914 seja inaugurado o novo jardim-escola». ${ }^{16}$ No entanto, a conclusão dos dois edifícios ${ }^{17}$ não terminou como previsto e só no ano seguinte foi noticiado «Neste Jardim-Escola, avenida Pedro Álvares Cabral, à Estrela, está aberta a matricula para crianças de 4 a 7 anos de idade, dos dois sexos. As respetivas condições acham-se patentes no mesmo Jardim-Escola, todos os dias úteis, até ao último do corrente mês, das 13 às 17 horas». ${ }^{18}$

A par disto, a preocupação com a harmonia das formas arquitetónicas, a beleza estética e a decoração dos espaços interiores e exteriores foi preponderante na escolha dos artistas que contribuíram para a sua concretização, tendo sido convidados os artistas João Vaz, Leal da Câmara e António Carneiro a contribuir para o embelezamento dos espaços.

Tendo a conclusão das obras do Museu João de Deus sido adiadas, aguardou-se pelo dia 11 de janeiro de 1917, 21ํaniversário do falecimento de João de Deus, para inaugurar solenemente a Escola-Monumento.

O projeto pedagógico, arquitetónico e higiene do jardim-escola

O Jardim-Escola foi concebido para crianças dos quatro aos oito anos, porque, na opinião de João de Deus Ramos, «é precisamente nesta idade que a criança está abandonada, senão a si própria, o que é o geral, pelo menos a uma educação perniciosa. É êste 0 êrro tão perigoso, de tão graves consequências, que 0 Jardim-Escola pretende emendar». ${ }^{19} \mathrm{O}$ projeto pedagógico inicial do Jardim-Escola era o de orientar a criança no sentido que ela crescesse intelectualmente, fisicamente e moralmente de forma harmoniosa e íntegra. A alfabetização era feita através da Cartilha Maternal ou Arte de Leitura, da Arte de Escrita e da Arte de Contas, todas obras pedagógicas de João de Deus. Para facilitar o processo de aprendizagem as crianças eram divididas em três secções. A $1^{\text {ạ }}$

\footnotetext{
${ }^{14}$ Lei de 15 de maio de 1912. Ministério do Interior. Direcção Geral da Instrução Secundária, Superior e Especial, 2a repartição. Diário do Govêrno no.116, de 18 de maio de 1912, p. 1797, concede gratuitamente à Associação das Escolas Móveis 5100 metros quadrados de terreno que o Estado possui na freguesia da Lapa, para Estabelecimento duma Escola-Monumento a João de Deus.

${ }^{15}$ O projeto foi aprovado pela Câmara Municipal de Lisboa a 5 de Fevereiro de 1913, assinado por Elísio de Campos (secretário da Associação de Escolas Móveis pelo Método João de Deus), mediante o pagamento de uma estampa fiscal da República Portuguesa de 100 réis. Foram apresentados os seguintes documentos: memória descritiva, projeto com corte A-B e corte C-D, planta do Jardim-Escola em escala de 1:100, tipo das asnas, planta do telhado e galeria e planta geral da localização.

${ }^{16}$ Relatório e Contas da Associação de Escolas Móveis, Bibliothecas Ambulantes e Jardins-Escolas, de 1 de julho de 1912 a 30 de junho de 1913, 4.

17 Jardim-Escola e Museu João de Deus.

18 «Instrução: Jardim-escola João de Deus», Diario de Noticias, 22/5/1915.

19 «Uma tarde no Jardim-Escola João de Deus: Uma grande obra educativa, sob a égide dum grande poeta, seguida por um grande educador - procurando remediar êrros que de longe veem - Escola portuguesa", 0 Comercio do Porto, 17/1/1941.
} 
secção, também denominada de Viveiro, para crianças de quatro a cinco anos, a $2^{\underline{a}}$ secção para crianças de seis a sete anos e a $3^{\underline{a}}$ secção para crianças de sete a oito anos. Em suma, João de Deus Ramos resumiu as linhas didáticas do método João de Deus como sendo «a educação dos sentidos, como resultante natural dos conhecimentos que vão surgindo, associados como o desenvolvimento psicológico e físico» e explicou que as didáticas dividiam-se em «Lições de coisas, Iniciação ao desenho, Trabalhos manuais educativos, Jogos de movimentos ao ar livre, Ginástica sueca, Ginástica rítmica (Dalcrose), Canto coral e Cartilha Maternal». Para o fundador do Jardim-Escola era fundamental «ensinar a ler, lendo, como se ensina a falar, e sempre raciocinando», a "obediência ativa» e o «ambiente escolar, criado pelas instalações (desde a arquitetura até aos detalhes do material escolar)" ${ }^{20}$

Por sua vez, o modelo arquitetónico do Jardim-Escola nada tinha a ver com o tipo de escolas existentes no país que amiúde, eram compostas, por apenas uma sala de aula para as quatro classes ou num andar de habitação adaptado à função escolar, mas carecendo de área de recreio. Apesar dos modelos de escolas propostos pelo arquiteto Adães Bermudes já apresentarem um jardim, eles são criticados por Formosinho: «Mas tão estreito são os limites do recreio a que impropriamente se queira dar aquele nome, que em parte nenhuma do país, ele teve ainda outra aplicação, que não fosse o servir para horta do professor.» ${ }^{21}$ Pelo contrário, no Jardim-Escola João de Deus ${ }^{22}$ "Nada, com efeito, the falta para ser uma escola moderna: Museu pedagogico, sala de banhos, cantina, sala de inspeção médica, etc. ${ }^{23}$ De facto, a organização do espaço do Jardim-Escola de Lisboa respeitava o modelo criado para todos os Jardins-Escolas, sendo composto por entrada, vestiário, museu, sala de leitura, sala de aritmética, banho, retretes, lavatório, cantina e cozinha. As crianças dispunham, ainda, de uma ampla zona de recreio. As crianças do Viveiro (1 ${ }^{\text {a }}$ secção) tinham aulas no museu (vulgarmente chamado de salão), enquanto as mais velhas, da $2^{\underline{a}}$ e $3^{\underline{a}}$ secção tinham aulas na sala de leitura e na sala de aritmética. As danças gesticuladas, assim como, as aulas de ginástica rítmica e de canto coral eram executadas no salão por crianças das três secções. Sob o ponto de vista arquitetónico, o edifício sem corredores permitia uma efetiva e permanente vigilância das crianças. Por outro lado, 0 aspeto decorativo das respetivas instalações, de bom gosto, mas sem luxo, permitia afirmar que em Portugal o Jardim-Escola tinha efetivado a «arte na escola». A decoração apelativa fazia com que a criança desenvolvesse gosto pela escola e estimulasse o sentido do belo.

\footnotetext{
${ }^{20}$ "Jardins-Escolas: Ouvindo o Dr. João de Deus Ramos, fundador do primeiro Jardim-escola, em Portugal», Correio da Estremadura, 16/1/1943.

${ }^{21}$ Francisco Júdice Formosinho, Inspecção Medica na Escola Primaria (Lisboa: Imprensa Lucas, 1909), 22.

${ }^{22}$ Refere-se à planta do Jardim-Escola João de Deus (Coimbra) que era idêntica à do Jardim-Escola João de Deus de Lisboa.

${ }^{23}$ Ibídem, 20.
} 
Relativamente à higiene, o Jardim-Escola de Lisboa estava a cargo do médico Francisco Júdice Formosinho ${ }^{24}$ que inspecionava as condições sanitárias do edifício e efetuava 0 exame clínico às crianças no início do ano escolar, apontando o seu parecer na caderneta médico-pedagógica pertencente a cada aluno. Pretendia-se detetar doenças contagiosas e avaliar a robustez física das crianças. 0 teste oftalmológico era feito usando o quadro optométrico do tenente-médico Mário Moutinho e do médico Sebastião Cabral da Costa Sacadura ${ }^{25}$.

A cubagem, o asseio, a ventilação, a boa iluminação natural através de amplas janelas e o mobiliário do Jardim-Escola eram alvo de frequentes elogios na imprensa e nos relatórios de quantos o visitavam. A escritora Carmen de Burgos ${ }^{26}$, que visitou o Jardim-Escola em 1920, afirmou no seu relatório enviado a João de Deus Ramos que:

Está todo limpio, claro y alegre, con algo de casa particular, de hogar acogedor y apacible. [...] El mismo tipo tienen todas aulas, el comedor, con las mesas resplandecientes con su servicio de porcelana blanca, y el cuarto de limpieza, verdadero modelo en su género. [...] Se comprende que los niños se sientan bien alli. La sensación de la casa, del ambiente, es tan necesária a la salud del cuerpo como a la salud espiritual. El niño se siente alli contento, alegre; la Escuela no tiene para él esa cosa de cárcel con que algunos establecimientos de este género pasan sobre el espiritu de los niños. ${ }^{27}$

\section{Educação dos sentidos, lições de coisas e dons de Froëbel}

Uma das práticas educativas mais marcantes do Jardim-Escola de Lisboa era que a educação dos sentidos antecedia a educação intelectual, semelhante ao que afirmavam Friedrich Froëbel e Maria Montessori. Os alunos do Viveiro aprendiam pela observação e comparação visual e táctil da forma, do tamanho e da cor dos objetos, pela comparação de sons musicais e ruídos, sua intensidade e duração, e de cheiros, estimulando os sentidos auditivo e olfativo. João de Deus Ramos considerava que:

\footnotetext{
Entre nós tem-se cometido o grave erro de mandar as crianças aprender a ler, sem, primeiro, as ensinar a ver. Todavia, há uma idade particularmente melindrosa, dos quatro aos oitos anos, quando a criança, maravilhada por tudo o que a rodeia, tudo pergunta, tudo quer saber, uma insaciável curiosidade. Vê e apalpa os objetos; desmancha-os, se pode, para avidamente, os observar, pois é levada por impulso irreprimível, a procurar a certeza na realidade. Este frenesim, este labor fervoroso, sem fadiga e sem fim, obriga a permanentes exercícios de linguagem; avulta e enriquece momento a momento o uso do vocabulário. [...] É assim que, nesta instituição, são ministradas às crianças lições de coisas, narrativas singelas, criteriosamente escolhidas, ao mesmo tempo que se faz a iniciação no desenho, a utilização
}

\footnotetext{
${ }^{24}$ Amigo de infância de João de Deus Ramos, estudou no Colégio de Campolide da Companhia de Jesus e formou-se na Escola Médico-Cirúrgica de Lisboa apresentando a tese de conclusão de curso em 1909 intitulada Inspecção Medica na Escola Primaria.

${ }^{25}$ Quadro Optométrico organizado pelos médicos Dr. Mário Moutinho, Diretor de Clínica Oftalmológica e Dr. Costa Sacadura, Inspector Geral de Sanidade Escolar. Aprovado pelo Ministério de Instrução Pública e mandado adoptar nas escolas. - Imprensa Nacional - 1913-1914. - A designação de Ministério de Instrução Pública foi usada de 1913 a 1936.

${ }^{26}$ Carmen de Burgos y Seguí (1867?-1932), professora primária, escritora e jornalista.

${ }^{27}$ Carmen de Burgos, Memoria. La escuela y los metodos del eminente pedagogo portugues João de Deus. Documento datilografado. [S.I. : s.n., 1920], 7-8.
} 
inteligente dos trabalhos manuais educativos, a seleção e execução dos jogos de movimento ao ar livre, a alfabetização metódica, etc. Numa palavra, tudo o que não possível fazer num lar doméstico. ${ }^{28}$

Ao dar «lições de coisas» aos alunos do Viveiro, as professoras seguiam uma ordem de crescente complexidade dos assuntos. Conversando naturalmente, procuravam, desenvolver o vocabulário familiar, introduzindo temas suscetíveis de interessar a curiosidade infantil e que pudessem ser compreendidos pelas crianças. Vários brinquedos de lata ${ }^{29}$ que costumavam estar expostos nas estantes dos armários do salão do Jardim-Escola eram colocados sobre as mesas do Viveiro e serviam de mote para a professora falar de vários temas, nomeadamente as profissões. 0 Jardim-Escola possuía uma coleção desses brinquedos com as profissões de telhador, sapateiro, latoeiro, ferreiro, alfaiate, torneiro e carpinteiro. Locomotivas, carruagens de comboios e um navio de guerra eram outros brinquedos que serviam o propósito das «lições de coisas». Uma balança de pratos e um conjunto de massas ${ }^{30}$, um higrómetro, barómetro e termómetro ${ }^{31}$, um disco de Newton, uma caldeira a vapor e uma coleção de sólidos geométricos eram materiais auxiliares de noções básicas de física. As «lições de coisas» não eram unicamente abordadas no Viveiro. Eram também dadas nas aulas da $2^{\underline{a}}$ e $3^{\underline{a}}$ secção a propósito dos trechos de leitura, dos trabalhos manuais, dos jogos educativos e duma maneira geral sempre que houvesse possibilidade para o fazer.

As «lições de coisas» têm por base o método intuitivo de Friedrich Froëbel, que consiste em ensinar as crianças a observar, educando-lhes os sentidos. As crianças no Jardim-Escola viam, sentiam, tocavam, mediam, comparavam, distinguiam para de seguida se desenvolver a inteligência através do raciocínio, da reflexão, da abstração. Este processo é muito idêntico ao desenvolvimento dos sentidos que Maria Montessori exercia na Casa dei Bambini, sobretudo no desenvolvimento táctil através de apalpação com os olhos fechados. Paralelamente, a passagem do conhecimento sensível para o conhecimento abstrato era também feita através dos Dons de Froëbel que têm uma gradação de dificuldade tanto da motricidade fina e equilíbrio, como de conceitos de espacialidade, de raciocínio matemático e geométrico. 01 1Dom é composto por seis bolas coloridas revestidas a lã e era usado para a aprendizagem das cores, estruturação espacial, lateralização, desenvolvimento verbal, e enriquecimento de vocabulário, jogos de memória, contagem, seriação e conjunto. $03^{\circ}$ Dom é composto por oito cubos, $04^{\circ}$ Dom por oito paralelepípedos e $05^{\circ}$ Dom por vinte e um cubos inteiros, três cubos partidos ao meio e outros três cubos partidos em quartos. Com o 3ㄴ, $4^{\circ}$ e $5^{\circ}$ Dons faziam-se construções tridimensionais, cujas formas iam dar aso à introdução de temas de conversa para desenvolver ideias e vocabulário, e à introdução de noções de unidade e frações, auxiliando o raciocínio lógico, permitindo a criação de problemas matemáticos e estimulando o cálculo mental.

\footnotetext{
${ }^{28}$ «Uma tarde no Jardim-Escola João de Deus: Uma grande obra educativa, sob a égide dum grande poeta, seguida por um grande educador - procurando remediar êrros que de longe veem - Escola portuguesa», 0 Comercio do Porto, 17/1/1941.

${ }^{29}$ Da marca GBN Bavaria dep., importados pela Ramos e Silva, Chiado no. 53-65, Lisboa.

${ }^{30}$ Da marca Force Kilog.

${ }^{31}$ Modelo D. R. G. M. 393302.
} 
Outra forma de aprendizagem de temáticas de flora, fauna e anatomia humana era feita pelo uso do «animatógrafo com projeções instrutivas».32 0 projetor de diapositivos, alimentado por arco voltaico com dois bastões pontiagudos de carvão, era colocado no varandim do primeiro andar e projetado para o salão onde todas as crianças aprendiam em simultâneo, ouvindo as explicações das professoras que não encontravam nenhum inconveniente na simultaneidade do ensino de meninos e meninas, em conjunto. Pelo contrário, reconheciam vantagens na coeducação dos sexos, designadamente, nesta fase ante-púbere, devido à idade e desde que houvesse uma eficaz fiscalização do comportamento dos alunos.

Depois da lição «vem o recreio, gratos intervalos de marcha, de folguedo no Jardim - com aproveitamento de noções de botânica». ${ }^{33}$ Com efeito, no espaço do recreio havia canteiros que as crianças cuidavam, jardinando e aprendendo.

\section{Alfabetização}

Tendo a criação do Jardim-Escola obedecido, entre outros objetivos, ao propósito de dar à Cartilha Maternal um lugar próprio na escola portuguesa, o método compreende 0 ensino da leitura e da escrita, que deve ser aprendido complementarmente. A Cartilha Maternal é um método analítico e sintético, silábico e fonético simultaneamente, apresentando o alfabeto por ordem das dificuldades prosódicas e ortográficas. João de Deus adotou uma nomenclatura especial para as letras que causa estranheza aos não iniciados no método, porque cada letra é conhecida pelos seus valores fonéticos, tendo os alunos que fixar os seus nomes mnemónicos. No entanto, essa característica facilita a produção escrita, pois evita que a criança dê erros ortográficos, uma vez que lhe é dado a conhecer as regras ortográficas. 0 uso dessa nomenclatura especial não é mais do que um processo de aprendizagem, uma vez que o aluno já saiba ler a professora deve indicar 0 devido nome das letras. Uma Cartilha Maternal de grandes dimensões era colocada num cavalete e a professora ensinava a ler, num ensino quase individualizado, uma vez que essa aprendizagem era feita aos pares ou em grupos de três ou quatro alunos no máximo, respeitando o ritmo de aprendizagem de cada um. A professora apontava com um ponteiro determinada palavra e explicava as suas regras fonéticas. Imediatamente após o ensino da leitura de uma determinada palavra, o aluno tinha que a colocar num contexto, construindo uma frase em que a palavra figurasse e aprendia a escrevê-la. A prática da cópia e do ditado faziam parte do quotidiano escolar.

Contudo, antes de aprenderem a escrever o que aprendiam a ler, as crianças aprendiam a grafia dos algarismos, porque como já estavam familiarizados com a contagem dos números desde o Viveiro, era natural que se começasse a grafar essa contagem. De facto, a iniciação da aprendizagem das operações numéricas da adição e subtração, por exemplo, era feita através de jogos educativos e das lições de coisas. Improvisavam-se pequenos problemas que não cansassem a memória do aluno, evitando repetições mecâ-

\footnotetext{
32 «Rapida visita ao Jardim-Escola João de Deus», Diario de Lisboa, 14/6/1929.

${ }^{33}$ Ibídem.
} 
nicas e sem sentido, recorrendo à ajuda de objetos para partir do concreto para o abstrato. Gradualmente as operações numéricas eram substituídas por fáceis problemas de cálculo mental. Porém nunca exigindo da criança maior esforço do que era próprio para a sua idade. Além do mais, respeitando o ensino gradual, partindo do mais simples para o mais complexo, os algarismos são mais fáceis de grafar.

As professoras tinham indicações para ensinar os alunos a sentarem-se direitos na carteira, ficando a folha de papel ligeiramente inclinada, devendo o braço fazer um ângulo e a mão deslizaria sem fazer grande pressão no papel. A Arte de Escrita apresentava um tipo de letra angulosa e ligeiramente inclinada para a direita. Apesar de já serem conhecidas as vantagens do ensino da letra direita, o Jardim-Escola continuou a ensinar letra inclinada. Era um objetivo primordial que terminado o último período letivo os alunos da $3^{a}$ secção do Jardim-Escola conseguissem ler e escrever com desenvoltura.

\section{Música, cantares, canto coral e jogos de movimento}

A formação musical estava presente em vários aspetos da rotina diária, nomeadamente, nos jogos de movimento, nas danças de roda, nas danças tradicionais, nas marchas, nos cantares, nas canções gesticuladas e no canto coral. Os jogos de movimento que eram adotados, quer no salão do Jardim-Escola, quer ao ar livre, tinham frequentemente música associada como por exemplo o barqueiro, o gatinho e o lobo. Outros porém, não careciam dessa associação. Os jogos que as crianças jogavam mais amiúde eram o jogo da princesa, o machado, a lenço, os cinco cantinhos, o gato e o rato, o cão e o coelho, a cabra-cega, o pilha três, assim como jogos em que era necessário o uso de arcos, cordas e bolas. A falta de um tempo de recreio livre era opção pedagógica de João de Deus Ramos, pois todo o tempo de recreio era despendido na execução de jogos, sob a orientação das professoras, ou seja, o recreio era sempre orientado. De facto, João de Deus Ramos acreditava que essa era a preferência das crianças, pois afirmou «Os jogos de movimento ao ar livre, ou em recinto apropriado, constituem, já de si, uma coordenação de atividades, com submissão a regras e a condições, correspondendo, aliás, à manifesta preferência da criança pelo jogo" ${ }^{34}$

As crianças aprendiam a cantar em uníssono e em polifonia acompanhadas a harmónio, porque João de Deus Ramos considerava que este instrumento tinha a vantagem de emitir um som que se aproximava ao da voz humana, tornando-se mais fácil o acompanhamento vocal infantil. No Jardim-Escola havia a preocupação da escolha de músicas para o canto coral que se adequassem à feição alegre e movimentada das crianças, assim como à escala e capacidade vocal média dos alunos que componham as secções. Assim sendo, na $1^{\underline{a}}$ e $2^{\underline{a}}$ secção cantava-se em uníssono, enquanto na $3^{\mathfrak{a}}$ secção poder-se-ia introduzir canções em polifonia, apesar de não ter sido muito frequente, devido à dificuldade acrescida. Um ponto assente é que não era ensinada senão música educativa, de preferência, regional portuguesa, para fortificar o espírito nacionalista. Para esse efeito, o Jardim-Escola possuía cancioneiros para o ensino do canto coral, sendo muitos deles da

${ }^{34}$ "Brinquedos», Boletim da Casa das Beiras, janeiro / março 1943, ano IX, III série - 1, 15. 
autoria do padre compositor Tomás Borba e de Silveira Pais, que musicaram poesias de poetas portugueses. Cantar poesia não só permitia o enriquecimento de vocabulário, mas também tornava as crianças eruditas.

Agradáveis e alegres eram as aulas de canto coral. Foi precisamente este o ambiente testemunhado pelo reporter do Diario de Lisboa ao visitar o Jardim-Escola de Lisboa:

Foi numa sessão de canto coral que a amabilidade das gentis professoras nos proporcionou, que ouvimos os próprios educandos, num belo orfeão em que não faltam excelentes solistas, fazer o elogio da Escola no seu hino, com música de Tomás del Negro e versos do jovem poeta Bastos Gonçalves. A nossa Escola é parecida, Com o palácio duma fada, Por isso gostamos dela, E nos pomos a dizer, A nossa Escola é tão bela, Que até dá gosto aprender. ${ }^{35}$

Complementarmente, as formas e as marchas escolares eram entendidas como necessárias e convenientes à disciplina coletiva do Jardim-Escola, porque de contrário os alunos apresentar-se-iam em estado de indisciplina, devido à sua desenvoltura natural. A este propósito João de Deus Ramos disse que se tratava de um «jardim-escola onde não há castigos, onde não há papões e as crianças não se insubordinam nem indisciplinam »36; entrevistado pelo Diario de Notícias afirmou que não havia «nem prémios nem castigos na educação da criança!». ${ }^{37}$ A ideia foi-Ihe transmitida por Théodore Daumers, diretor da Escola Comunal no.13 em Bruxelas, que ele conheceu pessoalmente a 14 de outubro de 1911. Nessa ocasião Daumers ofereceu a João de Deus Ramos um exemplar do relatório do primeiro Congresso Internacional de Educação Moral e Social decorrido em Londres, de 25 a 29 de setembro de 1908, no qual ele tinha participado e expresso o seu pensamento: «M. Daumers, directeur l'Ecole à Bruxelles, est adversaire des récompenses et des punitions. Nous devons apprendre aux enfants à faire le bien pour le bien, á se respecter eux-mêmes et à mériter l'estime des autres». ${ }^{38}$

Para além do mais, a questão da disciplina educativa da classe não deveria ser obtida por uma quietude passiva constante, pela exigência de sossego na sala de aula, mas por uma obediência ativa, que resultasse da atenção voluntária do aluno, mostrando um ponto comum com o método de «escola ativa» de Ovide Decroly. Devia-se cativar a atenção das crianças, explorar temas do seu interesse, deixar que elas se expressassem e se questionassem, numa atitude de curiosidade natural pelo saber e, por fim, que chegassem por elas próprias às conclusões. 0 professor não devia limitar a liberdade da criança, devia antes do mais, suprir as suas necessidades de atividade física, porque a criança é natu-

\footnotetext{
35 «Rapida visita ao Jardim-Escola João de Deus», Diario de Lisboa, 14/6/1929.

${ }^{36}$ "Uma tarde no Jardim-Escola João de Deus: Uma grande obra educativa, sob a égide dum grande poeta, seguida por um grande educador - procurando remediar êrros que de longe veem - Escola portuguesa", 0 Comercio do Porto, 17/1/1941.

${ }_{37}$ «Nem prémios nem castigos na educação da criança!» diz-nos o dr. João de Deus Ramos, director do JardimEscola João de Deus, a propósito do curso de didactica pré-primário que hoje inaugurou», Diario de Notícias, $15 / 2 / 1945$.

${ }^{38}$ Théodore Daumers, Le premier congrès international d'éducation morale et sociale: tenu a Londres du 25 au 29 septembre 1908: rapport présenté à l'administration communale de Bruxelles. (Bruxelles: Impr. du Progrès, 1910), 17.
} 
ralmente ativa. Seguindo esta linha de pensamento João de Deus Ramos escreveu que «a realidade visível, incontestável, é que nenhuma criança, com saúde, pode estar quieta. Exige-o o seu crescimento físico e também a natural inquietação dos sentidos que tudo buscam ver e palpar». ${ }^{39} \mathrm{E}$ acrescentou:

A educação tem o seu início, desde que os sentidos se apontam para ver, ouvir e tocar o mundo exterior. Ver o que é, como se chama, a forma do objecto, para que serve - é a natural consciência do contacto do espírito com a matéria e leva a criança a interrogar e a formular perguntas de dificílima resposta, pois atinge por vezes, aspectos de universalidade. ${ }^{40}$

Seguindo ainda a linha de pensamento de Ovide Decroly a escola estava em todo o lado, como por exemplo, na cozinha, na cantina e no pátio da escola. Do mesmo modo João de Deus Ramos afirmou que «todas as paredes são mestras». ${ }^{41}$

\section{Ginástica sueca e ginástica Dalcroze}

Nas primeiras duas décadas de existência do Jardim-Escola de Lisboa não há registo que houvesse uma preocupação especial com o exercício físico. Quando, em 1937, João de Deus Ramos inquiriu as professoras «Conhece, nas suas linhas essenciais, 0 que é o sistema de Ling? Os primeiros exercícios de ginástica sueca seriam aplicáveis nos Jardins-Escolas?» as professoras responderam que "Sobre o sistema de Ling é impossível responder visto não possuírmos conhecimentos que nos permitam ter uma opinião própria». ${ }^{42}$ Efetivamente, o primeiro professor de educação física só foi contratado em outubro de 1939, dando duas lições por semana. Chamava-se Augusto Adolfo Candela Alves Mimoso, possuía o Curso de Artilharia da Escola de Guerra e o Curso de Educação Física. Os primeiros exercícios de ginástica sueca, segundo o sistema de Pehr Henrik Ling (17761838) foram aplicados no Jardim-Escola a partir dessa data. As aulas eram dadas no salão e as crianças vestiam indumentária adequada à prática da ginástica, composta de calções, camisola e sapatilhas de borracha. A ginástica consistia na execução de movimentos de braços, tronco e pernas, de pé, agachados e deitados. A disposição dos alunos em xadrez permitia ao professor a observação de todos os alunos e verificar se executavam corretamente os exercícios. Pouco depois foi contratada uma jovem professora de ginástica. Contudo a partir de 1943 passaram as próprias professoras do Jardim-Escola a leccionar também a ginástica, pois já possuíam conhecimentos preciosos sobre jogos de movimento ao ar livre, sobre ginástica sueca segundo Ling, sobre ginástica rítmica segundo os ensinamentos do compositor e pedagogo Émile Jacques Dalcroze, (1865-1956) e sobre expressão corporal que Ihes tinham sido ensinados no Curso de Didática Pré-Primária.

\footnotetext{
39 «Brinquedos», Boletim da Casa das Beiras, janeiro / março 1943, ano IX, III série - 1, 13.

40 "Jardim-Escola João de Deus: Uma conferência do dr. João de Deus Ramos», O Trabalho, 9/3/1939.

41 "Jardins-Escolas: Ouvindo o Dr. João de Deus Ramos, fundador do primeiro Jardim-escola, em Portugal», Correio da Estremadura, 16/1/1943.

${ }^{42}$ Associação de Jardins-Escolas João de Deus, Questionario dirigido ás senhoras professoras dos JardinsEscolas para a "Conferencia Pedagógica» a realisar em fins de Setembro no Museu João de Deus. Documento dactilografado e manuscrito, Lisboa, 1937, 6.
} 


\section{Desenho, modelação e trabalhos manuais}

Estando João de Deus Ramos consciente de que «servindo o desenho para expressão do pensamento, e sendo tão útil e necessário, por vezes, como a própria palavra, é evidente que a vida das imagens no espírito infantil carece desse recurso de exteriorização desde a primeira infância». ${ }^{43}$ Para colmatar essa lacuna, adotou nos JardinsEscolas uma seriação de modelos de desenho, de gradual grau de dificuldade, que tinham «a utilidade que o aluno alcança ao saber traçar a reta primeiro que a curva, á qual sucede 0 desenho com perspetiva». ${ }^{44}$ Pensava ainda que 0 desenho desempenhava um papel preponderante no desenvolvimento da criança porque ajudava a disciplinar a atenção. O que implicava na prática, que as crianças começassem a aprender a desenhar copiando desenhos constituídos somente por segmentos de reta. Desenhos esses que iam aumentando de grau de complexidade. A professora desenhava uma figura no quadro enquanto as crianças tinham que copiar escrupulosamente o que viam, executando o desenho com rigor, replicando os mesmos traços e seguindo a mesma ordem pela qual a professora tinha executado o desenho. Podiam eventualmente, acrescentar algum elemento personalizado, algum detalhe, mas não havia muita margem para a liberdade criativa. Este processo foi apresentado no Congresso Pedagógico que João de Deus Ramos organizou em 1938, no Museu João de Deus, tendo sido noticiado «Como 0 autor da "Cartilha Maternal» 45 teve a intenção da escola ativa, ele, orador ${ }^{46}$, realizou essa obra no campo prático, procurou que o desenho como a leitura e a escrita fosse um ensino ativo". ${ }^{47}$ Durante 0 congresso, perante a assistência «foram desenhados objetos referentes às três séries" ${ }^{48} \mathrm{e}$ como conclusão do congresso foi aclamado que "Sobre a educação visual manual o Congresso aprova o método adotado nos Jardins-Escolas que tem o valor de resolver uma dificuldade, de há muito posta entre os artistas e os profissionais do ensino do desenho" ${ }^{49}$

Em vida João de Deus Ramos nunca referiu a origem o método de desenho adotado nos Jardins-Escolas. Somente, a sua filha, Maria da Luz de Deus Ramos referiu que:

[...] têm sido adoptados nos Jardins-Escolas de João de Deus, modelos de desenhos graduados em séries. São essas séries, constituídas por modelos copiados e adaptados do método de desenho dum artista flamengo, de nome Van Dycke (sic), que como modelo poderá ser contestado, mas que revela um poder de estilização, simplificando a silhueta, muito interessante e do agrado das crianças. $^{50}$

\footnotetext{
43 Ibídem, 16.

44 Ibídem.

45 João de Deus (1830-1896).

46 João de Deus Ramos (1878-1953).

${ }^{47}$ Congresso dos Jardins-Escolas João de Deus: Na sessão de ontem o sr. dr. João de Deus Ramos proferiu uma brilhante dissertação sobre «Lições de coisas». Diário de Notícias, 22/4/1938, 6.

48 Três séries de cadernos com desenhos feitos só com linhas retas e com gradual grau de dificuldade.

49 Ibídem, nota 51.

${ }^{50}$ Maria da Luz de Deus, Ensaios para a iniciação do ensino do desenho (Lisboa: Editorial "Os nossos filhos», Lda., 1947), 12.
} 
Uma pesquisa cuidada permite afirmar com segurança que os modelos de desenhos usados no Jardim-Escola foram copiados e adaptados da obra Hoe leer ik tekenen? Teekenvoorbeelden voor school en huis, publicada em 1904, pelo professor primário de Antuérpia Jan van Dijck, cuja versão alemã Wie lerne ich zeichnen? zeichenvorbilder für schule und haus incorpora o espólio bibliográfico do Museu João de Deus. A obra de Jan van Dijck é composta por três volumes, começando no desenho retilíneo e terminando no desenho curvilíneo. Porém João de Deus Ramos só possuía os dois primeiros volumes da versão alemã, que somente tinham exemplos de desenhos retilíneos. Escolheu os desenhos que Ihe pareceram mais interessantes e introduziu-lhes cariz nacional, colocando elementos da iconografia portuguesa ou adaptando à cultura nacional, como por exemplo colocando a cruz de Cristo na vela de um barco ou adaptando uma casa ao estilo arquitetónico duma casa rural portuguesa.

$\mathrm{O}$ desenho de série era unicamente usado nas duas primeiras secções. As crianças mais velhas, da $3^{\underline{a}}$ secção, já desenhavam à vista natureza morta, tal como folhas de árvores que colocavam na carteira ou nos estiradores, diante da folha de papel, e tentavam desenhá-la o mais fielmente possível, tanto nas dimensões como na forma. A transição devia ser sempre do modelo linear, desenhado na ardósia, para o modelo à vista, em vez de começar abruptamente, pelo modelo à vista, porque a criança teria dificuldade na execução desses desenhos sem ter treinado antes o olhar e a firmeza da mão em desenhos com exercícios progressivos. A escolha dos modelos de desenho à vista deveria obedecer à regra de partir dos mais fáceis para ao mais complexos e dificultosos.

As professoras deviam relacionar a prática do desenho do aluno com os seus trabalhos de modelação em barro, que serviam para exercitar a tridimensionalidade, com os trabalhos manuais e inclusive deviam prestar-se à introdução temas de lições de coisas. Tal como o desenho, os trabalhos manuais também serviam para educar a capacidade de atenção da criança e treinar a sua motricidade fina. Na lista de material usado no JardimEscola de Lisboa para esse fim constava papel vélin em fita e em quadrados, cartolina, papel de lustro, ráfia e barro, enquanto que os exercícios eram retirados de duas obras de referência de Álvaro Viana de Lemos, professor da Escola Normal de Lisboa no ano letivo 1914-15, intituladas Curso de trabalhos manuais : notas sobre ocupações frobelianas, modelação, cartonagem e trabalhos manuais, editada em 1915 pelo próprio autor e Trabalho manual escolar : trabalhos em papel, editada em 1929 pela Tipografia Reis Gomes. Os exercícios mais comuns que as crianças executavam eram os entrelaçamentos e as dobragens de crescente dificuldade criados por Froëbel.

\section{Religião e moral}

Sob o ponto de vista religioso João de Deus Ramos não considerava o Jardim-Escola como uma escola sem Deus, mas antes, uma escola para Deus, onde o sentimento de religiosidade era cultivado sem espírito de catequese, por considerar que essa não era função da escola. Por conseguinte, o currículo não contemplava o ensino da religião. 0 elemento que era utilizado para cultivar o sentimento da religiosidade era o culto do bem, 0 respeito e a bondade cristã. 
Uma vez que o Jardim-Escola adotava métodos e processos racionais, poder-se-ia pensar que tal sistema pudesse contrariar, de alguma forma, a convicção da fé religiosa, mas tal não acontecia. A criança recebe da sua família o sentimento religioso e por isso ama a Deus sobre todas as coisas e ao seu próximo como a si mesmo. Mas se por acaso não tem esse sentimento religioso, a criança pode amar a verdade sobre todas as coisas, numa atitude de serviço à ciência. A propósito deste assunto João de Deus Ramos disse, no Congresso Pedagógico de 1952 realizado no Museu João de Deus, que «as senhoras professoras dos Jardins-Escolas estão evidentemente ao serviço da ciência e ao serviço da verdade». ${ }^{51}$ No entanto, "se tiverem diante de si uma criança com um sentimento religioso arreigado, a sua obrigação é não contrariar esse sentimento, não comentá-lo de maneira a diminuir, a desprestigiar, por assim dizer, quem possa ter influído na formação religiosa da criança». ${ }^{52}$ A educação moral praticada no JardimEscola «não pode basear-se em orações de um determinado credo religioso, porque os Jardins-Escolas recebem crianças de todos os credos". ${ }^{53}$ Idealmente seria assim, mas na realidade a maioria da população era cristã, católica e, portanto, a percentagem de crianças de outras religiões seria residual ou nula. No entanto, João de Deus Ramos vai ainda mais longe dizendo que o fanatismo leva a ver tudo pela lógica da fé, e não pela razão. "Nós temos uma educação moral raciocinada, logo os métodos que adotamos têm que ser métodos racionais». ${ }^{54}$ Julgava ser esse um ponto inovador do seu modelo escolar porque «eu assisto a uma coisa que também não existe em parte nenhuma e que até me parece impossível que não exista, mas não existe». ${ }^{55} \mathrm{E}$ concluindo 0 seu pensamento afirmou que "a escola numa maneira geral não deve ser nem religiosa, nem laica, nem neutra». ${ }^{56}$ Reforça a ideia de que a escola não deve ser religiosa porque abre as portas a crianças de todos os credos. Além do mais o Jardim-Escola ensina crianças dos quatro aos oito anos de idade. «É uma idade própria, propícia ou não para 0 catecismo? Dir-se-á não». ${ }^{57}$

\section{Festas e exposições}

Apesar do projeto pedagógico não contemplar, propositadamente, o ensino de religião e moral, os valores cristãos de fraternidade, caridade e igualdade eram transmitidos às crianças através de contos e de práticas educativas, cuja festa de Natal era um exemplo cabal. Anualmente fazia-se uma árvore de Natal no salão do Jardim-Escola, decorando um pinheiro natural e colocando prendas embrulhadas junto ao seu tronco. A festa e distribuição de prendas fazia-se, habitualmente, no dia 24 de dezembro, onde eram recitadas poesias, culminando com um lanche na cantina. Aproveitava-se a ocasião de estarem

\footnotetext{
${ }^{51}$ João de Deus Ramos, Discurso: O sentimento religioso na educação moral: a disciplina escolar, 1952. Documento áudio transcrito por Elsa Rodrigues.

${ }^{52}$ Ibídem.

${ }^{53}$ Ibídem.

${ }^{54}$ Ibídem.

${ }^{55}$ Ibídem.

${ }^{56} \mathrm{lbidem}$.

${ }^{57}$ Ibídem.
} 
presentes elementos da direção da Associação, bem como dos pais e imprensa para se divulgar o que se aprendia no Jardim-Escola, tal como nos revela o seguinte relato: "houve danças e marchas infantis. Houve como de costume, uma exposição de trabalhos escolares, muitos dos quais a exemplificar o que ali se ensina e pratica para iniciação do gosto estético e culto da sensibilidade dos pequeninos». ${ }^{58}$

Por seu turno, as provas de aproveitamento de final de ano decorriam durante dois dias no início de julho e a entrada era pública. Familiares dos alunos e repórteres de imprensa escrita eram convidados a assistir aos exames que não só serviam para atestar os efetivos conhecimentos adquiridos ao longo do ano, mas também funcionavam como uma excelente ocasião de promoção e divulgação do projeto educativo junto da comunidade leitora desses periódicos. Numa dessas reportagens os exames foram descritos da seguinte maneira:

Prestaram as provas de desenho, de modelação em barro, sobre o método de Fröebel, crianças de 4 a 5 anos [...]. Às 15 horas prestaram provas de desenho, trabalhos manuais e modelação crianças de 8 e 9 anos [...] e de leitura e escrita. [...] Seguiram-se depois vários recitativos, cânticos e danças populares, com acompanhamento de órgão [...]. Às 15:30 foi servido o jantar às crianças na cantina [...]. ${ }^{59}$

Como o programa pedagógico não sofreu alterações substanciais durante o período de vida de João de Deus Ramos, as provas finais de ano refletiam essa constância. No início da década de 50 do século $X X$, as crianças do grupo $A$ e do grupo $B$ da $2^{-}$e $3^{\text {a }}$ secção, tinham que executar uma prova de Matemática que consistia na resolução dum problema, numa das operações numéricas, adição, subtração, multiplicação e divisão; uma prova Caligráfica através da cópia de um texto; uma prova Ortográfica através de um ditado; uma prova de Desenho através do sistema de desenhos de série e desenho à vista; e uma prova de Trabalhos Manuais com dobragens e entrelaçamentos em papel de lustro.

\section{Conclusões}

João de Deus Ramos foi um homem de uma determinação, iniciativa e resiliência enormes. A ele se deve a criação dos Jardins-Escolas. No entanto, não criou nenhuma pedagogia própria na verdadeira aceção da palavra. Não deixou um legado escrito e não fundamentou muitas das suas escolhas. É possível intuir o seu pensamento através de entrevistas publicadas em periódicos e conferências que proferiu ao longo da vida, mas não existe uma obra justificatória da metodologia João de Deus. O espírito de João de Deus Ramos era essencialmente prático. Sendo um homem de ação não perdeu tempo e energia em documentar as suas decisões. Porém, o acervo bibliográfico do Museu João de Deus revela as suas preocupações, orientações e influências pedagógicas.

\footnotetext{
58 «No Jardim-Escola João de Deus», Diario de Notícias, 22/12/1951.

59 «Festa escolar: No Jardim-Escola João de Deus: Provas anuais do aproveitamento dos alunos», A Imprensa Nova, 10/7/1924.
} 
Em entrevista asseverou que os Jardins-Escolas eram «Escolas diferencialmente portuguesas! Repilo tudo o que seja cópia servil «do que se faz lá fora», do que se faz no estrangeiro " ${ }^{60}$ e acrescentou "prefiro guiar-me, quanto possível por ideias próprias». ${ }^{61}$ Por outro lado, a iniciativa dos Jardins-Escolas João de Deus não renega do estrangeiro o que é universalmente adoptável ou adaptável. Comprovando esse pensamento, constata-se que apesar de na educação dos sentidos haver pontos de contacto com o Kindergarten de Froëbel e com a escola Montessori, João de Deus Ramos considerava que os Jardins-Escolas João de Deus eram escolas diferenciadamente portuguesas, porque apenas adotavam de Froëbel uma parte dos Dons, os que tinham formas geométricas.

A preocupação com a educação infantil em Portugal tinha tido a sua primeira manifestação na Carta de Lei, de 2 de maio de 1878, (Diário do Governo, no. 110, p. 1215) cujo artigo 68 determinava «as juntas gerais do distrito e as câmaras municipais promoverão a criação de asilos de educação, como auxiliares da escola primária, para acolherem as crianças dos três até seis anos». O primeiro Jardim de Infância foi inaugurado em Lisboa a 21 de abril de 1882 no Passeio da Estrela na sequência desta determinação. Porém, a existência de jardins de infância era residual, porque a iniciativa não teve manifesta continuidade. A abertura destes estabelecimentos de ensino era pontual e amiúde cingiam-se a seguir uma única pedagogia. Portanto, quando João de Deus Ramos delineou o plano de criação dos Jardins-Escolas João de Deus, pode dizer-se que com ele se começou a realizar o ensino infantil em Portugal, inteiramente de iniciativa privada.

Inovadora foi a escolha do termo Jardim-Escola, inspirado no termo Kindergarten criado por Froëbel, mas abarcando uma ideia mais ampla do que a de Jardim de Infância ou a de École Maternelle, porque nas suas escolas as crianças eram alfabetizadas em idade pré-escolar. A cumulação da educação pré-escolar com a alfabetização deu, portanto, origem ao termo Jardim-Escola.

No entanto, a ideia foi bastante contestada. A título de exemplo, Édouard Claparède (1873-1940) afirmou que:

[...] o uso prematuro da leitura inibe, paralisa, perturba, o desenvolvimento normal do espírito infantil. A leitura modifica completamente a atitude natural da criança: de ativa torna-se passiva; em vez de fazer experiências, armazena palavras na cabeça. Que vida ganharia o ensino se se proibisse dar livros às crianças antes dos 9 ou 10 anos! „

Seguidor da sua linha de pensamento, estava António Sérgio (1883-1969) que considerava os «métodos de cartilha, de vários autores e proveniências, coisas que o progresso já baniu e que devíamos fechar imediatamente num museu de antiguidades, como se

\footnotetext{
60 «A educação da criança. Deviam construir-se no país 50 jardins-escolas João de Deus diz-nos João de Deus Ramos", Diario de Lisboa, 5/12/1940.

${ }^{61}$ Ibídem.

62 António Sérgio, 0 ensino como factor do ressurgimento nacional: defeitos dos nossos métodos de ensino e maneira de os corrigir: linhas gerais de uma nova organização (Porto: Oficinas Gráficas, 1933), 29.
} 
fossem achas pré-históricas, como se fossem múmias de Faraós» ${ }^{63}$ e, a este propósito, fundamentou que:

em geral, esses métodos de cartilhas são de puro verbalismo, pecando, logo de entrada, contra dois princípios fundamentais: com efeito, introduzem as palavras sem as intuições correspondentes (muitas vezes, nas primeiras lições, palavras cuja intuição é impossível dar ao educando) e reúnem, no mesmo momento, termos cujos significados não apresentam nexo algum, nenhum fio de concentração. ${ }^{64}$

No entanto, condescendia que «ainda se se ensinasse a ler pelos métodos atuais, métodos vivos, atraentes, simples, - desde o Decroly ao Montessori, passando pelo método analítico que se liga à lição de coisas! » ${ }^{65}$ não seria despropositado 0 ensino da leitura. Portanto, não só a Cartilha Maternal era vista como obsoleta, podendo a criança aprender a ler através de um outro qualquer livro que lhe interessasse, como também reforça a ideia de Claparède ao afirmar que:

de experiências feitas parece dever concluir-se que quem só aprende a leitura aos 10 anos, aos 14 lê tão bem como se houvesse começado aos 7. Ora aos 10 anos toda a criança bem dirigida tem ansiedade de ler um livro, sobre qualquer assunto que a interessou: topará aí a sua cartilha. ${ }^{66}$

A sua contestação foi ainda mais longe ao considerar que «O abc deve ser o fruto, e não a raiz da educação. Mais tarde, para aperfeiçoamento da ortografia, composição, etc., 0 trabalho tipográfico é um excelente meio profissional». ${ }^{67}$ Ora, este pensamento opõe-se ferozmente às práticas educativas dos Jardins-Escolas João de Deus.

Pese embora as criticas ao conceito de Jardim-Escola e ao seu modelo educativo com uma alfabetização precoce, os Jardins-Escolas sobreviveram ao tempo, diferenciando-se do Kindergarten pelo ambiente educativo, mostrando que este devia ser similar ao da família, para que fossem verdadeiramente maternais os processos adotados.

Por fim, a ideia de adotar várias pedagogias e aplicá-las em benefício do desenvolvimento harmonioso das capacidades físicas, intelectuais e morais dos alunos, respeitando a individualidade de cada um foi inovadora. Foi original essa convergência de pedagogias. Enquadrando o projeto do Jardim-Escola João de Deus (Lisboa) na época, ele foi, sem dúvida, inovador, pois não havia nada de semelhante no país e punha em evidência a necessidade premente de criação duma política de educação pré-escolar de âmbito nacional.

\footnotetext{
${ }^{63}$ Ibídem, 29-30.

64 Ibídem, 30.

65 Ibídem, 29.

${ }^{66}$ António Sérgio, Cartas sobre a educação profissional, 13.

${ }^{67}$ Ibídem, 13-14.
} 
